\title{
Metal-Dithiolene Bonding Contributions to Pyranopterin Molybdenum Enzyme Reactivity
}

\author{
Jing Yang ${ }^{1} \mathbb{D}$, John H. Enemark ${ }^{2} \mathbb{D}$ and Martin L. Kirk ${ }^{1, *(\mathbb{D})}$ \\ 1 Department of Chemistry and Chemical Biology, The University of New Mexico, MSC03 2060, Albuquerque, \\ NM 87131-0001, USA; yangjing@unm.edu \\ 2 Department of Chemistry Biochemistry, University of Arizona, Tucson, AZ 85721, USA; \\ jenemark@email.arizona.edu \\ * Correspondence: mkirk@unm.edu; Tel.: +1-505-277-5992
}

Received: 2 February 2020; Accepted: 2 March 2020; Published: 5 March 2020

\begin{abstract}
Here we highlight past work on metal-dithiolene interactions and how the unique electronic structure of the metal-dithiolene unit contributes to both the oxidative and reductive half reactions in pyranopterin molybdenum and tungsten enzymes. The metallodithiolene electronic structures detailed here were interrogated using multiple ground and excited state spectroscopic probes on the enzymes and their small molecule analogs. The spectroscopic results have been interpreted in the context of bonding and spectroscopic calculations, and the pseudo-Jahn-Teller effect. The dithiolene is a unique ligand with respect to its redox active nature, electronic synergy with the pyranopterin component of the molybdenum cofactor, and the ability to undergo chelate ring distortions that control covalency, reduction potential, and reactivity in pyranopterin molybdenum and tungsten enzymes.
\end{abstract}

Keywords: metal-dithiolene; pyranopterin molybdenum enzymes; fold-angle; tungsten enzymes; electronic structure; pseudo-Jahn-Teller effect; thione; molybdenum cofactor; Moco

\section{Introduction}

It is now well-established that all known molybdenum-containing enzymes [1-3], with the sole exception of nitrogenase, contain a common pyranopterin dithiolene (PDT) (Figure 1) organic cofactor (originally called molybdopterin (MPT)), which coordinates to the Mo center of the enzymes through the sulfur atoms of the dithiolene fragment. To date, the PDT component [4] of the molybdenum cofactor (Moco) is the only known occurrence of dithiolene ligation in biological systems. This cofactor is also found in anaerobic tungsten enzymes, and it may be one of the most ancient cofactors in biology [5]. The study of metal-dithiolene compounds (metallodithiolenes) has undergone a recent renaissance, with their synthesis, geometric structure, spectroscopy, bonding, and electronic structure having been recently highlighted [4,6-20]. Here, we briefly review the discovery of metallodithiolene compounds $[13,21]$. This history is followed by a more extensive discussion of key investigations into the myriad roles of the dithiolene ligands in the structure, bonding and reactivity of metal compounds, using multiple spectroscopic techniques, as well as theoretical calculations. Throughout this review, the key implications of these results for Mo and $\mathrm{W}$ enzymes are discussed. 
<smiles>[R]O[R6]([H])([H])C[C@H]1O[C@@H]2Nc3nc(N)[nH]c(=O)c3N[C@H]2C(SC)=C1S[Na]</smiles>

Figure 1. The reduced tetrahydro form of the pyranopterin dithiolene (PDT) coordinated to Mo in the molybdenum cofactor (Moco). In the enzymes, the Mo ion can redox cycle between the $\mathrm{Mo}^{\mathrm{IV}}, \mathrm{Mo}^{\mathrm{V}}$, and $\mathrm{Mo}^{\mathrm{VI}}$ oxidation states.

In the early 1960s, several research groups reported intensely colored square planar metal complexes with chelating sulfur-donor ligands that could stabilize metal compounds in a range of formal oxidation states related by one-electron oxidation-reduction (i.e., redox) reactions (Figure 2) [22-24]. McCleverty gave these novel ligands the general name "dithiolene" in order to emphasize their delocalized electronic structures [25]. These ligands are also described as being "non-innocent" due to the participation of the dithiolene ligands in the multiple one-electron reactions of their metal complexes and the inability to assign a specific oxidation state to the metal ion or the dithiolene ligands [11].

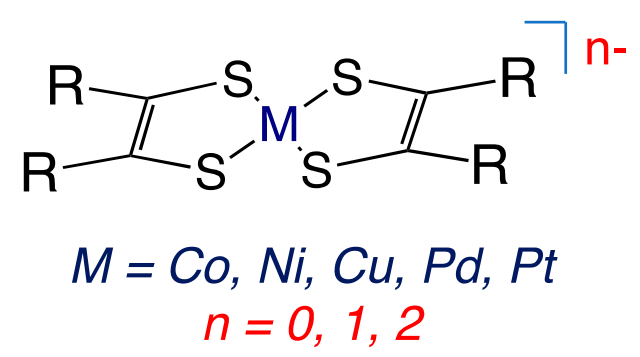

Figure 2. Square planer metallodithiolene complexes. $\mathrm{R}=\mathrm{CN}, \mathrm{CH}_{3}, \mathrm{Ph}, \mathrm{CF}_{3}$.

Importantly, these non-innocent dithiolene ligands can modulate the nature of the covalent bonding with transition metal ions via the various redox states accessible to the dithiolene (Figure 3) [13]. The ene-1,2-dithiolate is the reduced form of the ligand and possesses six $\pi$-electrons. This ligand form is both a $\sigma$-donor and $\pi$-donor that usually forms strong covalent bonds with an oxidized transition metal ion, as is observed in the active sites of most pyranopterin Mo and $\mathrm{W}$ enzymes (e.g., $\mathrm{Mo}(\mathrm{V}) / \mathrm{Mo}(\mathrm{VI})$-dithiolene bonds). The radical anion form with five $\pi$-electrons is usually found in molecules chelated by multiple dithiolene ligands, where extended delocalization of the $\pi$-electrons and mixed-valency assists in the stabilization of the metal-ligand bonds. The fully oxidized 1,2-dithione form of the ligand possesses only four $\pi$-electrons and can be described by two resonance structures (e.g., the 1,2-dithione and 1,2-dithiete). The low-lying empty $\pi^{*}$ orbitals of the $S=C$ bonds in the dithione can accept $\pi$-electron density from electron-rich low-valent transition metals $[16,17]$, thereby stabilizing such compounds. However, dithione-containing low-valent metal complexes are encountered much less frequently than high-valent transition metal ions coordinated by reduced forms of dithiolene ligands. 


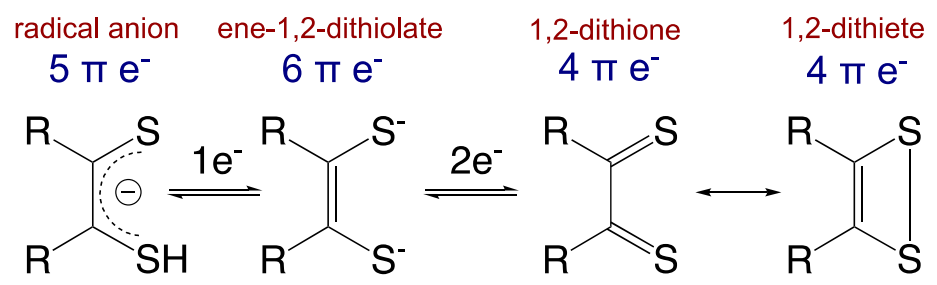

Figure 3. Dithiolene redox states and resonance structures for the oxidized dithione/dithiete forms. (Adapted with permission from Inorganic Chemistry, 2016, 55, 785-793. Copyright (2016) American Chemical Society).

In 1982, Johnson and Rajagopalan proposed that Moco consisted of the Mo ion coordinated by the dithiolene fragment of the PDT (Figure 1), from the results of an elegant series of degradative, analytical and spectroscopic studies of sulfite oxidase [26]. This proposed structure was subsequently confirmed by X-ray crystallography [27,28], and numerous examples are now known [29]. Molybdenum and tungsten enzymes are the only known examples of dithiolene coordination in biology, and given the "non-innocent" behavior of dithiolene ligands in simple metal compounds, one may ask what role does dithiolene coordination play in molybdenum enzymes? Through a series of examples involving small molecules and enzymes, we will address this important question and how it relates to control of metal-ligand covalency, reduction potentials, and reactivity in pyranopterin Mo and W enzymes.

\section{Mo-Dithiolene Bonding}

\subsection{Early Descriptions of Mo-Dithiolene Bonding}

Some insight into the role of dithiolene coordination in enzymes is provided by the organometallic compounds of the general formula $\mathrm{Cp}_{2} \mathrm{M}(\mathrm{bdt})$, where $\mathrm{Cp}$ is $\mathrm{C}_{5} \mathrm{H}_{5}{ }^{-}$, and $\mathrm{M}$ is either $\mathrm{Mo}, \mathrm{V}$ or Ti. The fold angle of the dithiolene ligand depends on the formal d-electron count of the metal, and this angle ranges from nearly planar $\left(9^{\circ}\right)$ for $\mathrm{Mo}\left(\mathrm{d}^{2}\right)$, to $35^{\circ}$ for $\mathrm{V}\left(\mathrm{d}^{1}\right)$, and $46^{\circ}$ for $\mathrm{Ti}\left(\mathrm{d}^{0}\right)$ (Figure 4$)$. Lauher and Hoffman [30] related this increase in the fold angle with decreased d-electron count to donation from the filled out-of-plane $\mathrm{S}_{\pi}{ }^{+}$orbital to the in-plane metal d-orbital (Figure 5). For the molybdenum enzymes, these model compound results imply that the Mo-dithiolene fold angle in Moco could be related to the formal oxidation state of the Mo atom, with $\mathrm{Mo}(\mathrm{VI})\left(\mathrm{d}^{0}\right)$ sites possessing a relatively large fold angle and $\mathrm{Mo}(\mathrm{V})\left(\mathrm{d}^{1}\right)$ and $\mathrm{Mo}(\mathrm{IV})\left(\mathrm{d}^{0}\right)$ sites possessing smaller fold angles. Accurate fold angles are difficult to determine for large protein molecules, but values ranging from $6-33^{\circ}$ have been calculated for various molybdenum enzymes [31]. The binding of substrate or inhibitors, and/or dynamic conformational changes in the protein, are expected to modulate the active site chelate fold angle and thereby affect enzyme reactivity [4,32].

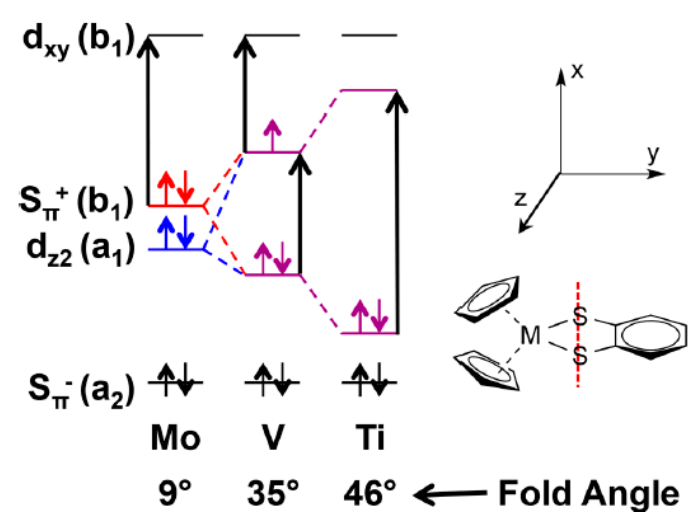

Figure 4. Fold angle distortions as a function of redox orbital electron occupancy in a series of $\mathrm{Cp}_{2} \mathrm{M}^{\mathrm{IV}}$ (bdt) complexes. (Adapted with permission from J. Am. Chem. Soc. 2018, 140, 14777-14788. Copyright (2018) American Chemical Society). 

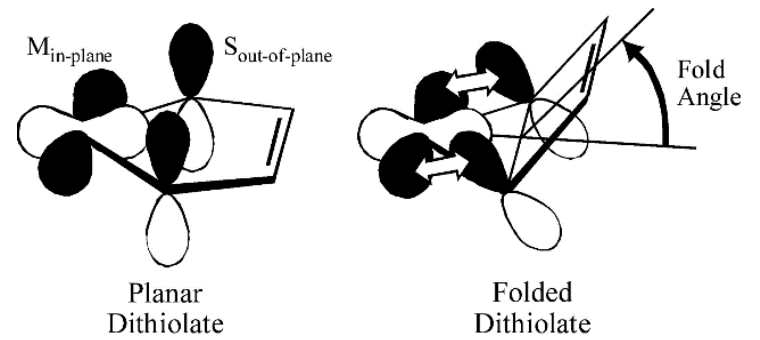

Figure 5. Pictorial description of how the ligand fold angle modulates the degree of mixing between the dithiolene out-of-plane $\mathrm{S}$ orbitals $\left(\mathrm{S}_{\pi}{ }^{+}\right)$and the in-plane $\mathrm{Mo}(\mathrm{xy})$ redox orbital. The chelate ring fold is along the dithiolene S-S vector. (Adapted with permission from Proc. Natl. Acad. Sci. USA. 2003, 100, 3719-3724. Copyright (2003) National Academy of Sciences.

\subsection{Spectroscopic Investigations of Mo-Dithiolene Bonding}

\subsubsection{Electron Paramagnetic Resonance (EPR) Spectroscopy}

An important spectroscopic signature of molybdenum enzymes, such as xanthine oxidase and sulfite oxidase, is a unique $\mathrm{Mo}(\mathrm{V})$ electron paramagnetic resonance (EPR) spectrum. The EPR spectra of the enzymes display a relatively large average g-value $\left(g_{\text {ave }}=1.97\right)$ and relatively small ${ }^{95,97} \mathrm{Mo}$ hyperfine interactions ( $h f i$ ) compared to the EPR spin-Hamiltonian parameters from typical inorganic $\mathrm{Mo}(\mathrm{V})$ complexes that possess hard $\mathrm{N}, \mathrm{O}$, and $\mathrm{Cl}$ donor ligands. The unique EPR parameters for molybdenum enzymes have been ascribed to covalent delocalization of electron density between the $\mathrm{Mo}(\mathrm{V})$ center and the sulfur atoms of the coordinated pyranopterin dithiolene unit [33]. The oxo-Mo(V) model compound $\mathrm{Tp} * \mathrm{MoO}(\mathrm{bdt})$ (Figure 6, where Tp* is hydrotris-(3,5-dimethyl-1-pyrazolyl)borate and bdt is 1,2-benzenedithiolate)) displays $\mathrm{Mo}(\mathrm{V})$ EPR spin-Hamiltonian parameters that are very similar to those observed in the enzymes. This supports the proposal of dithiolene coordination in Mo enzymes [34], which has been confirmed by X-ray crystal structures [2]. Recent multidimensional variable frequency pulsed EPR studies of sulfite oxidase, where the sulfur atoms of Moco have been isotopically labeled with ${ }^{33} \mathrm{~S}(\mathrm{I}=3 / 2)$, have provided direct experimental evidence for delocalization of $\mathrm{Mo}(\mathrm{V})$ spin density onto the $\mathrm{S}$ atoms of the dithiolene fragment of Moco [35,36]. Density functional theory (DFT) computations show spin polarization effects and strong covalent intermixing between the in-plane metal $\mathrm{d}_{\mathrm{xy}}$ orbital and out-of-plane $\mathrm{p}_{\mathrm{z}}$ orbitals of the PDT dithiolene $\mathrm{S}$ atoms, which provide a mechanism for the observation of a significant ${ }^{33}$ S hyperfine interaction $[12,36]$.

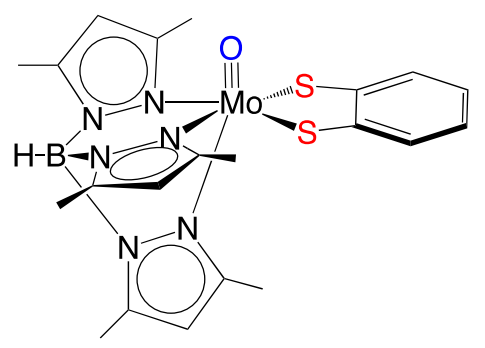

Figure 6. The $\mathrm{Tp}^{*} \mathrm{Mo}^{\mathrm{V}} \mathrm{O}(\mathrm{bdt})$ model. Note that the apical oxo ligand can be changed to a terminal sulfido or nitrosyl to probe the electronic structure of the Mo-dithiolene unit. The bdt ligand can also be conveniently interchanged with a large variety of other dithiolenes.

\subsubsection{Electronic Absorption and Resonance Raman Spectroscopies}

Experimental investigation of the electronic structures of the Mo centers of enzymes is difficult because of the intense absorptions from other chromophores (e.g., the $b$-type heme in sulfite oxidase and iron sulfur centers and FAD in xanthine oxidase) [37-41]. However, the effects of dithiolene coordination on electronic structure have been investigated for model oxo-Mo(V) compounds (Figure 6) by electronic absorption, XAS, magnetic circular dichroism (MCD), and resonance Raman (rR) 
spectroscopies [12,14-17,32,33,42-51]. For Tp*MoO(bdt), the electronic absorptions at 19,400 $\mathrm{cm}^{-1}$ (Band 4) and 22,100 $\mathrm{cm}^{-1}$ (Band 5) are assigned to $S \rightarrow$ Mo charge transfer bands (Figure 7A) [12]. These assignments have been confirmed by rR spectroscopy (Figure 7A,B), which shows three resonantly enhanced vibrations at $362.0,393.0$, and $931.0 \mathrm{~cm}^{-1}$. The lower frequency vibrations $\left(v_{1}\right.$ and $\left.v_{6}\right)$ can be assigned to symmetric S-Mo-S stretching and bending vibrations, and the $931.0 \mathrm{~cm}^{-1}$ frequency $\left(v_{3}\right)$ is primarily the $\mathrm{Mo} \equiv \mathrm{O}$ stretch. Figure $7 \mathrm{C}$ shows a molecular orbital diagram that is consistent with the spectroscopic data of Figure 7A,B. Band 5 of Figure 7A is assigned as $\psi_{o p}{ }^{a "} \rightarrow \psi_{x z}{ }^{a "}, \psi_{y z}{ }^{a}$ (blue arrow, Figure 7C), a transition which formally results in the promotion of an electron from an out-of-plane dithiolene molecular orbital to the nearly degenerate Mo $d_{x z, y z}$-based orbitals, which are strongly antibonding with respect to the apical $\mathrm{Mo} \equiv \mathrm{O}$ bond. This band assignment is supported by the $\mathrm{rR}$ enhancement of $v_{3}$ (squares) with excitation into Band 5 (Figure 7A,B). The preferential enhancement of vibrations $v_{1}$ (diamonds) and $v_{6}$ (circles) upon excitation at $514.5 \mathrm{~nm}$ (Figure 7A,B) supports assignment of Band 4 as the electronic transition $\psi_{\mathrm{ip}}{ }^{\mathrm{a}^{\prime \prime}} \rightarrow \psi_{\mathrm{xy}}{ }^{\mathrm{a}^{\prime}}$ (red arrow, Figure $7 \mathrm{C}$ ), which promotes an electron from the antisymmetric in-plane dithiolene orbital $\left(\psi_{\mathrm{ip}}{ }^{\mathrm{a}^{\prime \prime}}\right)$ to the half-filled in-plane Mo $\mathrm{d}_{\mathrm{xy}}\left(\psi_{\mathrm{xy}}{ }^{\mathrm{a}^{\prime}}\right)$ orbital. The intensity of this electronic transition illustrates the covalency of in-plane metal-dithiolene bonding and suggests that such a pseudo- $\sigma$-mediated process could play a role in one-electron transfer steps of enzyme catalysis.
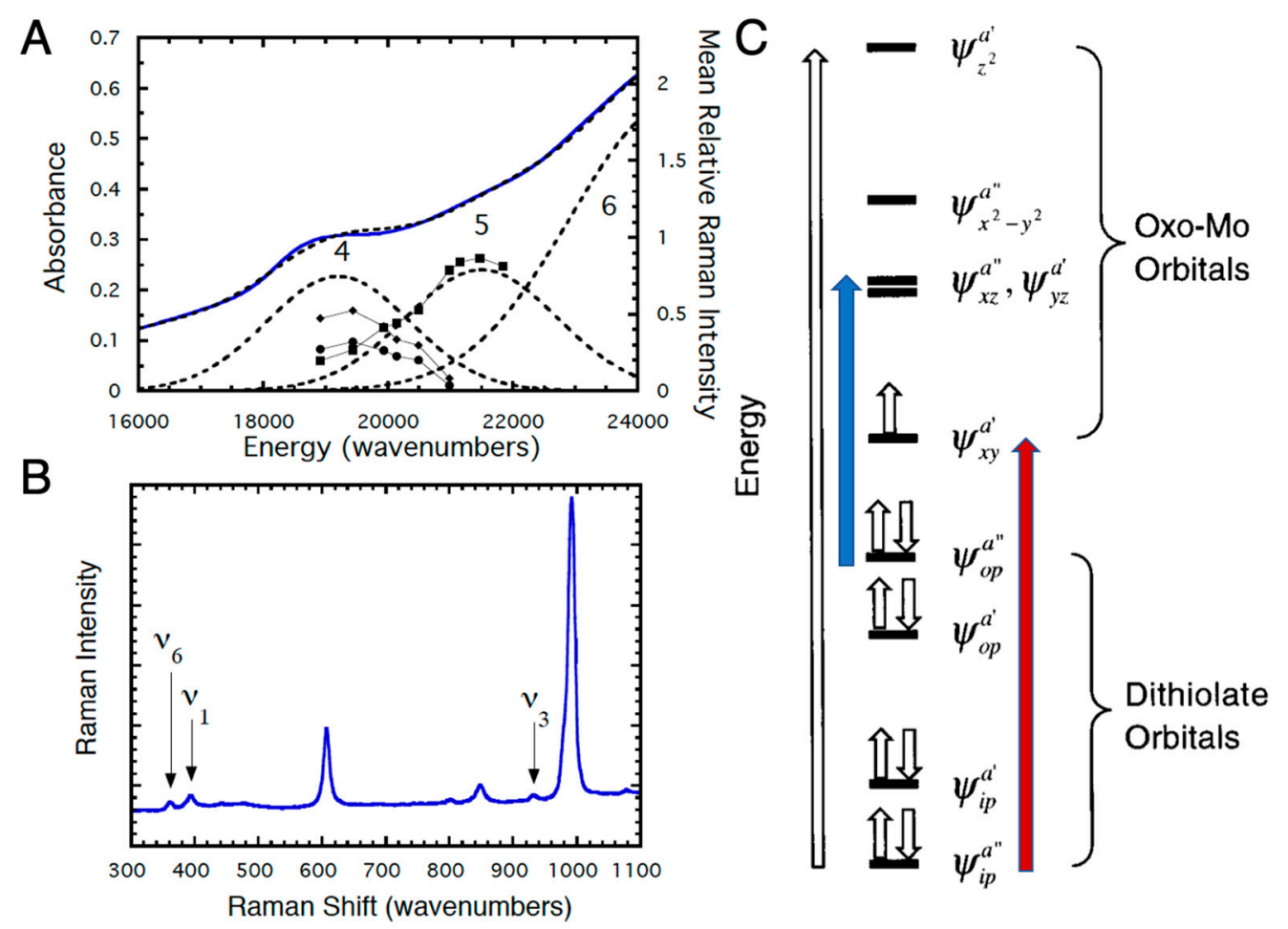

Figure 7. (A) Solid state resonance Raman profiles and 5K mull electronic absorption spectrum for $\mathrm{Tp}^{*} \mathrm{Mo}^{\mathrm{V}} \mathrm{O}(\mathrm{bdt})$. (B) Resonance Raman spectrum for $\mathrm{Tp}^{*} \mathrm{Mo}^{\mathrm{V}} \mathrm{O}(\mathrm{bdt})(293 \mathrm{~K})$ using $514.5 \mathrm{~nm}$ excitation $(75 \mathrm{~mW})$. (C) General molecular orbital diagram for $\mathrm{Tp}^{*} \mathrm{Mo}^{\mathrm{V}} \mathrm{O}$ (dithiolene) complexes. The $\mathrm{z}$-axis is oriented along the $\mathrm{Mo} \equiv \mathrm{O}$ bond and the energies of the molecular orbitals are not drawn to scale. Transitions are described in the text. (Adapted with permission from Inorganic Chemistry, 1999, 38, 1401. Copyright (1999) American Chemical Society).

\section{Synergistic Interactions between the Dithiolene and Pterin Components of the PDT}

Electronic coupling between the dithiolene and the pterin components of the PDT is most prevalent in the dihydropyranopterin form of the PDT $[4,15,20,29,52]$. This coupling is dramatically reduced in a tetrahydropyranopterin due to the loss of extended $\pi$-conjugation in these systems. Two-electron oxidation of the tetrahydro pyranopterin component of the PDT can result in 
an unusual asymmetric dithiolene known as the "thiol-thione" form that leads to bond and electronic asymmetry in the metal-dithiolene core $[4,15,52]$. As depicted in Figure 8, the two-electron oxidized 10,10a-dihydropyranopterin can undergo an induced internal redox reaction upon protonation at the N-5 position that involves a subsequent charge transfer between the dithiolene chelate and the piperazine ring of the pterin. This protonation results in a dominant monoanionic thiol-thione chelate form of the ligand when bound to Mo or W. This thiol-thione character can also occur in the absence of protonation by the concept of resonance, which may also be described as configurational mixing between the thiol-thione and dithiol states. This type of thiol-thione chelate has been observed and studied in a small molecule Mo(IV) systems [4,15,20,52]. In these systems, excited state thiol-thione character was shown to be admixed into the ground state configuration using a variety of spectroscopic and computational probes of the electronic structure. The analysis of the data indicates that a two-electron oxidized pterin is inherently electron withdrawing, allowing for a low-lying dithiolene $\rightarrow$ pterin intraligand charge transfer (ILCT) state to mix with the ground state to provide a variable degree of thiol-thione character in the electronic ground state.<smiles>Nc1nc2c(c(=O)[nH]1)N=C1C(S)=C(S)C(P)OC1N2</smiles>

(a)

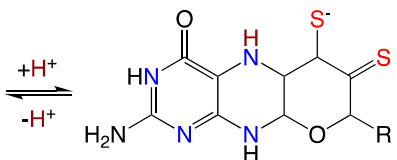

(b)

Figure 8. Oxidized PDT ligands: dihydropyranopterin (a) and protonated dihydropyranopterin (b) yielding the thiol/thione.

Definitive spectroscopic signatures are associated with the presence of a dihydropterin form of the PDT ligand. It is observed that the dithiolene $\rightarrow$ pterin intraligand charge transfer (ILCT) band is intense $\left(E=20,000-27,500 \mathrm{~cm}^{-1} ; \varepsilon \sim 10,000-16,000 \mathrm{M}^{-1} \mathrm{~cm}^{-1}\right)$ [52], and there is considerable resonance enhancement of numerous Raman vibrations that can be assigned as originating from pterin and dithiolene $\mathrm{C}=\mathrm{C}$ and $\mathrm{C}=\mathrm{N}$ vibrations. Key resonance enhanced vibrational modes that can be used to characterize the presence of dihydropterin thiol-thione character in the enzymes include the $1508 \mathrm{~cm}^{-1}$ and $1549 \mathrm{~cm}^{-1}$ pyranopterin-dithiolene stretching frequencies that were observed in this Mo(IV) cyclized pyranopterin dithiolene model compound. This oxidized pyran ring closed form of the PDT has yet to be definitively observed in any pyranopterin Mo enzyme, but its presence would have profound implications on the electronic structure of the Mo site. Namely, the change in ligand charge from -2 to -1 leads to an asymmetric reduction in the charge donated by the monoanionic ligand compared to the dianionic dithiolene. Charge effects on oxygen atom transfer catalysis have recently been explored in model compounds showing dramatic rate enhancements in the oxidative half reaction that leads to substrate reduction [53]. This reactivity correlates with a large shift in the $\mathrm{Mo}(\mathrm{VI} / \mathrm{V})$ reduction potential between cationic $\left[\mathrm{Tpm}^{*} \mathrm{MoO}_{2} \mathrm{Cl}\right]^{+}\left(-660 \mathrm{mV}\right.$ vs. $\left.\mathrm{Fc}^{+} / \mathrm{Fc}\right)$ and charge neutral $\mathrm{Tp}^{*} \mathrm{MoO}_{2} \mathrm{Cl}\left(-1010 \mathrm{mV}\right.$ vs. $\left.\mathrm{Fc}^{+} / \mathrm{Fc}\right)$ [53]. The same effect on redox potential and reactivity would be expected in enzymes that could adopt an oxidized PDT with a thiol-thione configuration. The presence of a thiol-thione form of the PDT in an enzyme would also have a considerable impact on the active site electronic structure, and enable the pyranopterin to play a more significant role in catalysis by fine-tuning the Mo redox potential and providing a $\pi$-pathway for electron transfer regeneration of the active site [52]. Additionally, the asymmetry in the dithiolene (thiol/thione) charge donation would be expected to result in a significant trans effect or trans influence on oxo or sulfido ligands that are coordinated to the Mo or W ion and oriented trans to the thione sulfur. 


\section{The Electronic Buffer Effect and Fold Angle Distortions}

\subsection{Photoelectron Spectroscopy (PES) Studies}

A common structural feature of the large group of pyranopterin Mo enzymes that catalyze a wide range of oxidation/reduction reactions in carbon, sulfur, and nitrogen metabolism is coordination by the sulfur atoms of one (or two) unique dithiolene groups derived from the side chain of a novel substituted pterin (PDT, Figure 1). Given the electronic lability of the dithiolene, a possible role of dithiolene coordination in molybdoenzymes is to buffer the influence of other ligands and changes in the formal oxidation state of the metal. Gas-phase photoelectron spectroscopy (PES) is a powerful tool for probing metal-ligand covalency in isolated molecules. Gas-phase ultraviolet PES of the molybdenum model complexes with the general formula $\mathrm{Tp} \mathrm{P}^{*} \mathrm{MoE}(\mathrm{tdt}$ ) (Figure 6, where $\mathrm{E}=\mathrm{O}, \mathrm{S}$, or $\mathrm{NO}$, and $\mathrm{tdt}=3,4$-toluenedithiolate), exhibit nearly identical first ionization energies $(6.88-6.95 \mathrm{eV})$ even though there is a dramatic difference in the electronic structure properties of the axial ligand. Collectively, these results have provided direct experimental evidence for the "electronic buffer" effect of dithiolene ligands [54].

Additional evidence for the electronic buffer effect of dithiolene ligands has been provided by gas-phase core and valence electron ionization energy measurements of the series of molecules $\mathrm{Cp}_{2} \mathrm{M}$ (bdt) (Figure 4, $\mathrm{Cp}=\eta^{5}$-cyclopentadienyl, $\mathrm{M}=\mathrm{Ti}, \mathrm{V}, \mathrm{Mo}$, and bdt = benzene-1,2-dithiolate). Comparison of the gas-phase core and valence ionization energy shifts provides a unique quantitative energy measure of valence orbital overlap interactions between the metal and the sulfur orbitals that is separated from the effects of charge redistribution. The results explain the large amount of sulfur character in the redox-active orbitals and the electronic buffering of oxidation state changes in metal-dithiolene systems. The experimentally determined orbital interaction energies also reveal a previously unidentified overlap interaction of the predominantly sulfur HOMO of the bdt ligand with the filled $\pi$ orbitals of the Cp ligands, suggesting that direct dithiolene interactions with other ligands bound to the metal could be significant for other metallodithiolene systems in chemistry and biology [55].

\subsection{A Large Fold Angle Distortion in a Mo(IV)-Dithione Complex}

$\mathrm{Mo}(\mathrm{IV})$-dithione complexes are much rarer than $\mathrm{Mo}(\mathrm{V}) / \mathrm{Mo}(\mathrm{VI})$-dithiolene complexes. Recently, a detailed spectroscopic and computational study was performed on a novel Mo(IV)-dithione complex, $\mathrm{MoO}(\mathrm{SPh})_{2}\left({ }^{\mathrm{i}} \mathrm{Pr}_{2} \mathrm{Dt}^{0}\right)$ (where ${ }^{\mathrm{i}} \mathrm{Pr}_{2} \mathrm{Dt}^{0}=N, N^{\prime}$-isopropylpiperazine-2,3-dithione) [17]. The structure of this unusual molecule was determined by x-ray crystallography and displays a remarkably large dithiolene fold angle $\left(\eta=70^{\circ}\right)$. This large fold angle was compared to that observed in more than 75 other metallodithiolene complexes found in the Cambridge crystallographic database, where fold angles were found to range from $0.3^{\circ}$ to $37.3^{\circ}$ with an average value for $\eta$ of $12.5^{\circ}$ [17]. The large fold angle distortion in the metallodithiolene ring of $\mathrm{MoO}(\mathrm{SPh})_{2}\left({ }^{\mathrm{i}} \mathrm{Pr}_{2} \mathrm{Dt}^{0}\right)$ is reflected in its unusual electron absorption spectrum. The combination of an electron rich $\mathrm{Mo}(\mathrm{IV})$ center and electron donating thiolate (SPh) ligands results in the presence of low-energy $\mathrm{Mo}(\mathrm{IV}) \mathrm{d}\left(\mathrm{x}^{2}-\mathrm{y}^{2}\right) \rightarrow$ dithione MLCT and thiolate $\rightarrow$ dithione LL'CT transitions as a result of the strong $\pi$-acceptor character of the dithione ligand. These spectral assignments are supported by resonance Raman profiles constructed for the $378 \mathrm{~cm}^{-1} \mathrm{~S}-\mathrm{Mo}-\mathrm{S}$ symmetric stretch and the $945 \mathrm{~cm}^{-1} \mathrm{Mo} \equiv \mathrm{O}$ stretch in addition to the results of TDDFT computations. The donor-acceptor nature of the complex was revealed in a molecular orbital fragments analysis using a donor fragment, $\left[(\mathrm{PhS})_{2} \mathrm{Mo}(\mathrm{IV})\right]^{2+}(\mathrm{F} 1)$ and an acceptor fragment, $\left[{ }^{\mathrm{i}} \mathrm{Pr}_{2} \mathrm{Dt}^{0}\right]$ (F2). The analysis showed that $21 \%$ of the F1 HOMO was mixed into the F2 fragment LUMO at a $70^{\circ}$ fold angle. In contrast, only $5 \%$ of the F1 HOMO was mixed into F2 fragment LUMO in a planer configuration $\left(\eta=0^{\circ}\right)$, correlating the effective $\pi$-acceptor ability of the dithione with the ligand fold angle. The effects of this HOMO-LUMO mixing also affects the HOMO-LUMO gap, with the HOMO-LUMO gap increasing at larger fold angles (Figure 9). The increased covalency that results from the fold angle distortion represents an example of a strong pseudo-Jahn-Teller effect, vide 
infra, involving vibronic coupling between the ground state and a low-energy excited state in the non-distorted $\left(\eta=0^{\circ}\right)$ geometry of this molecule. A scan of the potential energy surface as a function of this fold angle distortion coordinate results in an asymmetric double well potential (Figure 10), with the global minimum representing a ground state geometry with the dithione ligand fold distorted toward the apical oxo ligand. Thus, an oxidized dithione form of the PDT present in an enzyme active site would be expected to possess a very large ligand fold angle, unless the polypeptide enforces a more planer fold angle geometry.

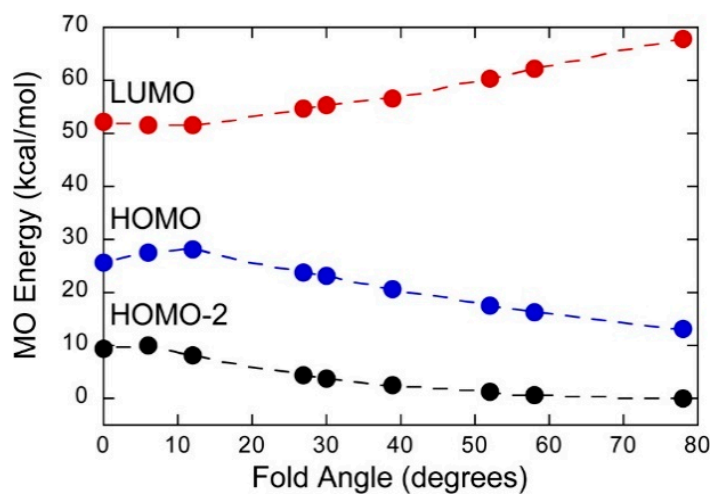

Figure 9. Frontier orbital energies as a function of fold angle in $\mathrm{Mo}^{\mathrm{IV}} \mathrm{O}(\mathrm{SPh})_{2}\left({ }^{\mathrm{i}} \mathrm{Pr}_{2} \mathrm{Dt}^{0}\right)$, which possesses a dithione $\pi$-acceptor ligand. (Adapted with permission from Inorganic Chemistry, 2016, 55, 785-793. Copyright (2016) American Chemical Society).

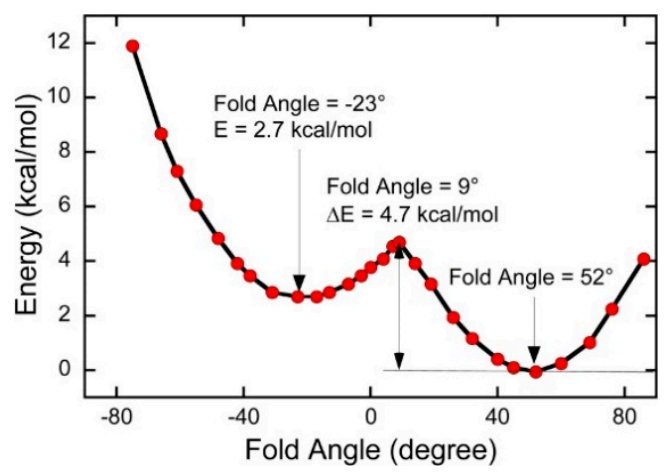

Figure 10. A double well in the ground state potential energy surface of $\mathrm{Mo}^{\mathrm{IV}} \mathrm{O}(\mathrm{SPh})_{2}\left({ }^{\mathrm{i}} \operatorname{Pr}_{2} \mathrm{Dt}^{0}\right)$ as a function of the ligand fold angle. (Adapted with permission from Inorganic Chemistry, 2016, 55, 785-793. Copyright (2016) American Chemical Society).

\subsection{Low-Frequency Pyranopterin Dithiolene Vibrational Modes in Xanthine Oxidase/Dehydrogenase}

Low-frequency dithiolene distortions that are coupled to large electron density changes at the Mo ion represent an example of the electronic buffer effect [54], and have been probed in bovine xanthine oxidase $(\mathrm{XO})$ and $R$. capsulatus xanthine dehydrogenase $(\mathrm{XDH})$ using resonance Raman spectroscopy [40]. Computations have shown that exciting into a low-energy $\mathrm{Mo}(\mathrm{IV}) \rightarrow$ product metal-to-ligand charge transfer (MLCT) band results in a large degree of change transfer from the $\mathrm{Mo}(\mathrm{IV}) \mathrm{HOMO}$ to the product LUMO, resulting in an excited state with significant $\mathrm{Mo}(\mathrm{V})$ hole character (e.g., $\left.\mathrm{Mo}(\mathrm{IV})-\mathrm{P}^{0} \rightarrow \mathrm{Mo}(\mathrm{V})-\mathrm{P} \cdot\right)$. Thus, the optical charge transfer process mimics the instantaneous one-electron oxidation of the Mo ion, which is encountered in the electron transfer reactions of the enzymes.

The $\mathrm{Mo}(\mathrm{IV}) \rightarrow$ 2,4-TV and $\mathrm{Mo}(\mathrm{IV}) \rightarrow$ 4-TV (2,4-TV = 2,4-thioviolapterin; 4 -TV = 4-thioviolapterin) MLCT bands are red-shifted relative to the Mo(IV) $\rightarrow$ violapterin MLCT band [39,40,56-59]. The red-shift of the $\mathrm{Mo}^{\mathrm{IV}}-2,4-\mathrm{TV}$ and $\mathrm{Mo}^{\mathrm{IV}}-4$-TV MLCT bands eliminates spectral overlap with the absorption envelope of the $2 \mathrm{Fe}-2 \mathrm{~S}$ spinach ferredoxin clusters and FAD. The elimination of the 
FAD fluorescence background and spurious signals deriving from $2 \mathrm{Fe}-2 \mathrm{~S}$ vibrations contributing to the Raman spectrum allow for the acquisition of very high-quality resonance Raman data. Multiple low-frequency (200-400 $\mathrm{cm}^{-1}$ ) Raman vibrations are observed to be enhanced when using laser excitation on resonance with the $\mathrm{Mo}(\mathrm{IV}) \rightarrow$ product MLCT band [40], and these have been assigned as a vibrational mode involving dithiolene folding, $\mathrm{Mo} \equiv \mathrm{O}$ rocking, and pyranopterin motions (Band $\mathrm{A}$ : $\left.\mathrm{Mo}^{\mathrm{IV}}-4-\mathrm{TV}=234 \mathrm{~cm}^{-1} ; \mathrm{Mo}^{\mathrm{IV}}-2,4-\mathrm{TV}=236 \mathrm{~cm}^{-1}\right)$, a ring distortion vibration that possesses both Mo-SH and pyranopterin motions (Band $\mathrm{B}: \mathrm{Mo}^{\mathrm{IV}}-4-\mathrm{TV}=290 \mathrm{~cm}^{-1} ; \mathrm{Mo}^{\mathrm{IV}}-2,4-\mathrm{TV}=286 \mathrm{~cm}^{-1}$ ), the symmetric S-Mo-S dithiolene core stretching vibration (Band C: $\mathrm{Mo}^{\mathrm{IV}}-4-\mathrm{TV}=326 \mathrm{~cm}^{-1} ; \mathrm{Mo}^{\mathrm{IV}}-2,4-\mathrm{TV}=326$ $\mathrm{cm}^{-1}$ ), and the corresponding asymmetric S-Mo-S dithiolene stretch (Band D: $\mathrm{Mo}^{\mathrm{IV}}-4-\mathrm{TV}=351 \mathrm{~cm}^{-1}$; $\mathrm{Mo}^{\mathrm{IV}}-2,4-\mathrm{TV}=351 \mathrm{~cm}^{-1}$ ) (Figure 11). Thus, the instantaneous generation of a hole on the Mo center $\left(\mathrm{Mo}(\mathrm{IV})-\mathrm{P}^{0} \rightarrow \mathrm{Mo}(\mathrm{V})-\mathrm{P} \cdot\right)$ by photoexcitation is felt by the dithiolene chelate and extends all the way to the amino terminus of the PDT. The most resonantly enhanced mode in this spectral region is Band C, the symmetric S-Mo-S dithiolene core stretching, and the frequency of this mode and Band $\mathrm{D}$ are similar to those observed in $\mathrm{Tp}{ }^{*} \mathrm{MoO}(\mathrm{bdt})[12,32]$, which were assigned as the chelate ring symmetric S-Mo-S stretching and bending vibrations, respectively. Band A is significant, since it possesses dithiolene ring folding character indicating that electron density changes at Mo are buffered by a distortion along this low-frequency coordinate, as has been observed in the various model systems described in this review. These observations strongly support an electron transfer role for the PDT in catalysis, with the dithiolene contributing to the Mo-S covalency necessary for increasing the electronic coupling matrix element for electron transfer $\left(H_{D A}\right)$ and to affect the Mo reduction potential via the covalency in the Mo- $S_{\text {dithiolene }}$ bonds.

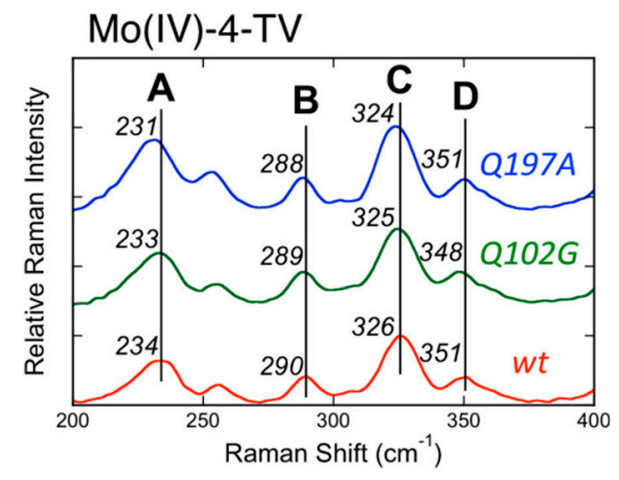

(a)

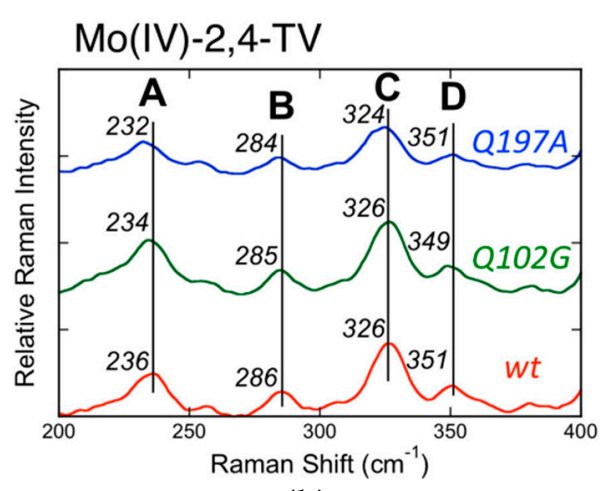

(b)

Figure 11. Low-frequency rR spectra for wt, Q102G, and Q197A XDH, Mo ${ }^{I V}-4-T V$ (a) and Mo ${ }^{I V}-2,4-T V$ (b). Raman spectra were collected on resonance with the Mo(IV) $\rightarrow$ P MLCT band using $780 \mathrm{~nm}$ laser excitation (Adapted with permission from Inorganic Chemistry, 2017, 56, 6830-6837. Copyright (2017) American Chemical Society).

\section{Vibrational Control of Covalency}

A combination of $\mathrm{MCD}$, electronic absorption, electron paramagnetic resonance, resonance Raman, and photoelectron spectroscopies has been used in conjunction with theory to reveal vibrational control of metal-ligand covalency in a series of $\mathrm{Cp}_{2} \mathrm{M}(\mathrm{bdt})$ complexes $\left(\mathrm{M}=\mathrm{Ti}, \mathrm{V}, \mathrm{Mo} ; \mathrm{Cp}=\eta^{5}-\mathrm{C}_{5} \mathrm{H}_{5}\right)$ [60] (Figure 4). The work is important because it has allowed for a detailed understanding of how redox orbital electron occupancy (Ti(IV) $=\mathrm{d}^{0}, \mathrm{~V}(\mathrm{IV})=\mathrm{d}^{1}, \mathrm{Mo}(\mathrm{IV})=\mathrm{d}^{2}$,) affects the nature of the M-dithiolene bonding scheme at parity of the ligand set and at parity of charge. In this series of complexes, large changes in the metallodithiolene fold angle and electronic structure are observed as electrons are successively removed from the redox orbital (Figure 4). These electron occupancy effects on the fold angle distortion are now understood in terms of the pseudo-Jahn-Teller effect (PJT). PJT-derived molecular distortions originate from the mixing of the electronic ground state $\left(\Psi_{0}\right)$ with specific excited states $\left(\Psi_{\mathrm{i}}\right)[61,62]$. The ground state-excited state energy gap $(2 \Delta)$, the matrix elements $\left(F_{0 \mathrm{i}}\right)$ of the 
vibronic contribution to the force constant $(F)$, and the primary non-vibronic force constant $\left(K_{0}\right)$ all govern the degree of the ligand fold distortion according to:

$$
\begin{gathered}
F_{0 i}=\left\langle\Psi_{0}\left|\frac{\partial H}{\partial Q}\right| \Psi_{i}\right\rangle \\
F^{2}>\Delta \cdot K_{0}
\end{gathered}
$$

At the critical threshold defined by Equation (2), the metallodithiolene centers of $\mathrm{Cp}_{2} \mathrm{M}(\mathrm{bdt})$ can distort along the dithiolene fold angle coordinate to yield a double well potential energy surface (Figure 12), and the magnitude of the PJT distortion is maximized by a large $F$, a small $\Delta$, and a small $K_{0}$. Thus, the PJT distortion in these $\mathrm{Cp}_{2} \mathrm{M}(\mathrm{bdt})$ complexes effectively couples soft fold angle bending modes in the M-dithiolene chelate ring to the inherent electronic structure of the system via the d-electron count. Importantly, the mixing of low-energy charge transfer states into the ground state by the PJT effect controls the covalency of the M-S bonds.

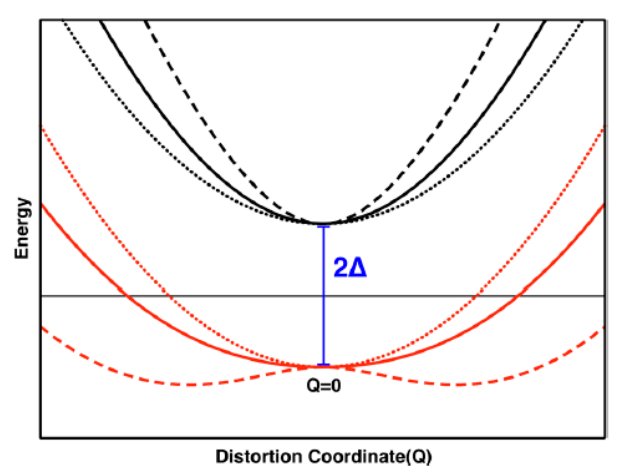

Figure 12. The excited state (black) and ground state (red) potential energy surfaces associated with varying values of $\mathrm{F}^{2}$ (Dotted: $\mathrm{F}^{2}=0$, solid: $\mathrm{F}^{2}=\Delta \cdot \mathrm{K} 0$, dashed: $\mathrm{F}^{2}=2 \Delta \cdot \mathrm{K} 0$ ) When the condition $\mathrm{F}^{2}$ $>\Delta \cdot \mathrm{K} 0$ is met one observes that the single-well ground state potential energy surface distorts into a double-well potential. The $\mathrm{F}^{2}>\Delta \cdot \mathrm{K} 0$ criteria describe a strong PJT effect. (Adapted with permission from J. Am. Chem. Soc. 2018, 140, 14777-14788. Copyright (2018) American Chemical Society).

One of the unique aspects of Mo-S and W-S bonding is the small energy gap between filled dithiolene-based orbitals and the lowest energy metal-based orbital, which naturally leads to low-energy charge transfer states that can mix with the ground state. Mode softening along the dithiolene fold coordinate is important in pyranopterin Mo and $\mathrm{W}$ enzymes since this leads to a potential energy surface where a large range of dithiolene fold angles may be sampled without paying a prohibitive energy penalty. This effect is maximized when $F^{2} \cong \Delta \cdot K_{0}$. Thus, a low-energy pathway is operative that can minimize energetically unfavorable reorganizational energy contributions along the reaction coordinate, which accompany redox changes at the metal ion. As mentioned previously, these fold angle distortions have been shown to be kinematically coupled to low frequency pyranopterin modes in $\mathrm{XO}$ and contribute to low-energy barriers for electron transfer regeneration of the active site. However, in the enzymes there may be either a competing or additive relationship between active site distortions that are driven via the d-electron count of the metal ion and distortions that are imposed by the protein. Vibronic coupling effects that derive from different occupancy numbers for the redox-active orbital will function to modulate the enzyme reduction potential in the oxidative and reductive half reactions of pyranopterin Mo and W enzymes, and this occurs by modulating the degree of metal-ligand covalency via low-frequency distortions at the active site. 


\section{Conclusions}

This review focuses on the electronic structures, molecular structures, and spectroscopic properties of well-characterized metallodithiolene compounds in order to provide deep insight into the role(s) of metal-dithiolene bonding in pyranopterin dithiolene containing enzymes (Figure 1). The discovery, in the early 1960s, that transition metal dithiolene compounds undergo a series of one-electron oxidation-reduction reactions (Figure 2), provided the first evidence for the "non-innocence" of dithiolene ligands and the highly covalent nature of metal-dithiolene bonding. Additional links between metal-dithiolene covalency and electronic and molecular structure were posited from theoretical studies of bent metallocene-dithiolene compounds (Figure 4) by Lauher and Hoffman in 1976 [30], who related metal-dithiolene chelate ring "folding" with the metal ion d-electron configuration. Investigations of Mo dithiolene compounds by electronic absorption, resonance Raman, and EPR spectroscopies showed that $S \rightarrow$ Mo charge transfer bands dominate the visible spectrum and that there is substantial delocalization of spin density onto the $S$ atoms of the dithiolene. Recent comprehensive studies of bent metallocene-dithiolene compounds have shown that low-energy ligand fold distortions arise from a pseudo-Jahn-Teller (PJT) effect, which involves vibronic coupling of the electronic ground state with electronic excited states to control metal-ligand covalency [60] (Section 5). This vibronic coupling process may play critical roles in the catalytic cycles of pyranopterin Mo and $\mathrm{W}$ enzymes by dynamic and/or static modulation of redox potentials and providing a superexchange pathway for electron transfer through the PDT framework. However, greater understanding of how geometric and electronic structure control reactivity, and define function in Mo and W enzymes, will require linking the concepts that have been developed for metallodithiolenes to the emerging results from studies of well-characterized compounds that mimic the pterin component of PDT (Section 3). Exploring the synergistic interactions between the dithiolene and pterin components of the PDT and the metal ion will be challenging, but such research promises to provide important insights into these critically important enzymes.

Author Contributions: J.H.E., J.Y., and M.L.K. collectively conceived and drafted this article. All authors have read and agreed to the published version of the manuscript.

Funding: M.L.K.'s research contributions to this article were funded by the National Institutes of Health (R01-GM-057378).

Conflicts of Interest: The authors declare no conflict of interest.

\section{References}

1. Hille, R.; Schulzke, C.; Kirk, M.L. Molybdenum and Tungsten Enzymes; The Royal Society of Chemistry: Cambridge, UK, 2017.

2. Hille, R.; Hall, J.; Basu, P. The Mononuclear Molybdenum Enzymes. Chem. Rev. 2014, 114, 3963-4038. [CrossRef]

3. Kirk, M.L.; Stein, B. The Molybdenum Enzymes. In Comprehensive Inorganic Chemistry II, 2nd ed.; Jan, R., Kenneth, P., Eds.; Elsevier: Amsterdam, The Netherlands, 2013; pp. 263-293. [CrossRef]

4. Nieter Burgmayer, S.J.; Kirk, M.L. The Role of the Pyranopterin Dithiolene Component of Moco in Molybdoenzyme Catalysis. In Metallocofactors that Activate Small Molecules: With Focus on Bioinorganic Chemistry; Ribbe, M.W., Ed.; Springer International Publishing: Cham, Switzerland, 2019; pp. 101-151. [CrossRef]

5. Weiss, M.C.; Sousa, F.L.; Mrnjavac, N.; Neukirchen, S.; Roettger, M.; Nelson-Sathi, S.; Martin, W.F. The physiology and habitat of the last universal common ancestor. Nat. Microbiol. 2016, 1, 116. [CrossRef]

6. Fourmigue, M. Mixed cyclopentadienyl/dithiolene complexes. Coord. Chem. Rev. 1998, 180, 823-864. [CrossRef]

7. Faulmann, C.; Cassoux, P. Solid-State Properties (Electronic, Magnetic, Optical) of Dithiolene Complex-Based Compounds. Prog. Inorg. Chem. 2004, 52, 399-490. 
8. Deplano, P.; Pilia, L.; Espa, D.; Mercuri, M.L.; Serpe, A. Square-planar d(8) metal mixed-ligand dithiolene complexes as second order nonlinear optical chromophores: Structure/property relationship. Coord. Chem. Rev. 2010, 254, 1434-1447. [CrossRef]

9. Sproules, S.; Wieghardt, K. o-Dithiolene and o-aminothiolate chemistry of iron: Synthesis, structure and reactivity. Coord. Chem. Rev. 2010, 254, 1358-1382. [CrossRef]

10. Sproules, S.; Wieghardt, K. Dithiolene radicals: Sulfur K-edge X-ray absorption spectroscopy and Harry's intuition. Coord. Chem. Rev. 2011, 255, 837-860. [CrossRef]

11. Eisenberg, R.; Gray, H.B. Noninnocence in Metal Complexes: A Dithiolene Dawn. Inorg. Chem. 2011, 50, 9741-9751. [CrossRef]

12. Inscore, F.E.; McNaughton, R.; Westcott, B.L.; Helton, M.E.; Jones, R.; Dhawan, I.K.; Enemark, J.H.; Kirk, M.L. Spectroscopic evidence for a unique bonding interaction in oxo-molybdenum dithiolate complexes: Implications for sigma electron transfer pathways in the pyranopterin dithiolate centers of enzymes. Inorg. Chem. 1999, 38, 1401-1410. [CrossRef]

13. Kirk, M.L.; McNaughton, R.L.; Helton, M.E. The Electronic Structure and Spectroscopy of Metallo-Dithiolene Complexes. In Progress in Inorganic Chemistry: Synthesis, Properties, and Applications; Stiefel, E.I., Karlin, K.D., Eds.; John Wiley and Sons: Hoboken, NJ, USA, 2004; Volume 52, pp. 111-212.

14. Peariso, K.; Helton, M.E.; Duesler, E.N.; Shadle, S.E.; Kirk, M.L. Sulfur K-edge spectroscopic investigation of second coordination sphere effects in oxomolybdenum-thiolates: Relationship to molybdenum-cysteine covalency and electron transfer in sulfite oxidase. Inorg. Chem. 2007, 46, 1259-1267. [CrossRef]

15. Matz, K.G.; Mtei, R.P.; Leung, B.; Burgmayer, S.J.N.; Kirk, M.L. Noninnocent Dithiolene Ligands: A New Oxomolybdenum Complex Possessing a Donor Acceptor Dithiolene Ligand. J. Am. Chem. Soc. 2010, 132, 7830-7831. [CrossRef]

16. Mtei, R.P.; Perera, E.; Mogesa, B.; Stein, B.; Basu, P.; Kirk, M.L. A Valence Bond Description of Dizwitterionic Dithiolene Character in an Oxomolybdenum-Bis(dithione) Complex. Eur. J. Inorg. Chem. 2011, 2011, 5467-5470. [CrossRef]

17. Yang, J.; Mogesa, B.; Basu, P.; Kirk, M.L. Large Ligand Folding Distortion in an Oxomolybdenum Donor Acceptor Complex. Inorg. Chem. 2016, 55, 785-793. [CrossRef]

18. Yang, J.; Kersi, D.K.; Richers, C.P.; Giles, L.J.; Dangi, R.; Stein, B.W.; Feng, C.; Tichnell, C.R.; Shultz, D.A.; Kirk, M.L. Ground State Nuclear Magnetic Resonance Chemical Shifts Predict Charge-Separated Excited State Lifetimes. Inorg. Chem. 2018, 57, 13470-13476. [CrossRef]

19. Yang, J.; Kersi, D.K.; Giles, L.J.; Stein, B.W.; Feng, C.J.; Tichnell, C.R.; Shultz, D.A.; Kirk, M.L. Ligand Control of Donor-Acceptor Excited-State Lifetimes. Inorg. Chem. 2014, 53, 4791-4793. [CrossRef]

20. Matz, K.G.; Mtei, R.P.; Rothstein, R.; Kirk, M.L.; Burgmayer, S.J.N. Study of Molybdenum(4+) Quinoxalyldithiolenes as Models for the Noninnocent Pyranopterin in the Molybdenum Cofactor. Inorg. Chem. 2011, 50, 9804-9815. [CrossRef]

21. Kirk, M.L. Spectroscopic and Electronic Structure Studies of Mo Model Compounds and Enzymes; The Royal Society of Chemistry: Cambridge, UK, 2016; pp. 13-67.

22. Schrauzer, G.N.; Mayweg, V. Reaction of Diphenylacetylene with Nickel Sulfides. J. Am. Chem. Soc. 1962, 84, 3221. [CrossRef]

23. Gray, H.B.; Billig, E.; Williams, R.; Bernal, I. Spin-Free Square Planar Cobaltous Complex. J. Am. Chem. Soc. 1962, 84, 3596. [CrossRef]

24. Davison, A.; Holm, R.H.; Edelstein, N.; Maki, A.H. Preparation and Characterization of 4-Coordinate Complexes Related by Electron-Transfer Reactions. Inorg. Chem. 1963, 2, 1227. [CrossRef]

25. McCleverty, J.A. Metal 1,2-Dithiolene and Related Complexes. Prog. Inorg. Chem. 1968, 10, 49-221.

26. Johnson, J.; Rajagopalan, K. Structural and Metabolic Relationship Between the Molybdenum Cofactor and Urothione. Proc. Natl. Acad. Sci. USA 1982, 79, 6856-6860. [CrossRef]

27. Chan, M.K.; Mukund, S.; Kletzin, A.; Adams, M.W.W.; Rees, D.C. Structure of a Hyperthermophilic Tungstopterin Enzyme, Aldehyde Ferredoxin Oxidoreductase. Science 1995, 267, 1463-1469. [CrossRef]

28. Romao, M.J.; Archer, M.; Moura, I.; Moura, J.J.G.; Legall, J.; Engh, R.; Schneider, M.; Hof, P.; Huber, R. Crystal Structure of the Xanthine Oxidase Related Aldehyde Oxidoreductase from D. gigas. Science 1995, 270, 1170-1176. [CrossRef] 
29. Rothery, R.A.; Stein, B.; Solomonson, M.; Kirk, M.L.; Weiner, J.H. Pyranopterin conformation defines the function of molybdenum and tungsten enzymes. Proc. Natl. Acad. Sci. USA 2012, 109, 14773-14778. [CrossRef]

30. Lauher, J.W.; Hoffmann, R. Structure and Chemistry of Bis(Cyclopentadienyl)-MLn Complexes. J. Am. Chem. Soc. 1976, 98, 1729-1742. [CrossRef]

31. Joshi, H.K.; Cooney, J.J.A.; Inscore, F.E.; Gruhn, N.E.; Lichtenberger, D.L.; Enemark, J.H. Investigation of metal-dithiolate fold angle effects: Implications for molybdenum and tungsten enzymes. Proc. Natl. Acad. Sci. USA 2003, 100, 3719-3724. [CrossRef]

32. Inscore, F.E.; Knottenbelt, S.Z.; Rubie, N.D.; Joshi, H.K.; Kirk, M.L.; Enemark, J.H. Understanding the origin of metal-sulfur vibrations in an oxo-molybdenurn dithiolene complex: Relevance to sulfite oxidase. Inorg. Chem. 2006, 45, 967. [CrossRef]

33. Peariso, K.; Chohan, B.S.; Carrano, C.J.; Kirk, M.L. Synthesis and EPR characterization of new models for the one-electron reduced molybdenum site of sulfite oxidase. Inorg. Chem. 2003, 42, 6194-6203. [CrossRef]

34. Cleland, W.E.; Barnhart, K.M.; Yamanouchi, K.; Collison, D.; Mabbs, F.E.; Ortega, R.B.; Enemark, J.H. Syntheses, Structures, and Spectroscopic Properties of 6-Coordinate Mononuclear Oxo-Molybdenum(V) Complexes Stabilized by the Hydrotris(3,5-Dimethyl-1-Pyrazolyl)Borate Ligand. Inorg. Chem. 1987, 26, 1017-1025. [CrossRef]

35. Enemark, J.H. Consensus structures of the $\mathrm{Mo}(\mathrm{V})$ sites of sulfite-oxidizing enzymes derived from variable frequency pulsed EPR spectroscopy, isotopic labelling and DFT calculations. Dalton Trans. 2017, 46, 13202-13210. [CrossRef]

36. Klein, E.L.; Belaidi, A.A.; Raitsimring, A.M.; Davis, A.C.; Kramer, T.; Astashkin, A.V.; Neese, F.; Schwarz, G.; Enemark, J.H. Pulsed Electron Paramagnetic Resonance Spectroscopy of S-33-Labeled Molybdenum Cofactor in Catalytically Active Bioengineered Sulfite Oxidase. Inorg. Chem. 2014, 53, 961-971. [CrossRef] [PubMed]

37. Jones, R.M.; Inscore, F.E.; Hille, R.; Kirk, M.L. Freeze-Quench Magnetic Circular Dichroism Spectroscopic Study of the "Very Rapid" Intermediate in Xanthine Oxidase. Inorg. Chem. 1999, 38, 4963-4970. [CrossRef] [PubMed]

38. Yang, J.; Dong, C.; Kirk, M.L. Xanthine oxidase-product complexes probe the importance of substrate/product orientation along the reaction coordinate. Dalton Trans. 2017, 46, 13242-13250. [CrossRef]

39. Dong, C.; Yang, J.; Reschke, S.; Leimkühler, S.; Kirk, M.L. Vibrational Probes of Molybdenum Cofactor-Protein Interactions in Xanthine Dehydrogenase. Inorg. Chem. 2017, 56, 6830-6837. [CrossRef]

40. Dong, C.; Yang, J.; Leimkühler, S.; Kirk, M.L. Pyranopterin Dithiolene Distortions Relevant to Electron Transfer in Xanthine Oxidase/Dehydrogenase. Inorg. Chem. 2014, 53, 7077-7079. [CrossRef]

41. Helton, M.E.; Pacheco, A.; McMaster, J.; Enemark, J.H.; Kirk, M.L. An MCD Spectroscopic Study of the Molybdenum Active Site in Sulfite Oxidase: Insight into the Role of Coordinated Cysteine. J. Inorg. Biochem. 2000, 80, 227-233. [CrossRef]

42. Sugimoto, H.; Sato, M.; Asano, K.; Suzuki, T.; Mieda, K.; Ogura, T.; Matsumoto, T.; Giles, L.J.; Pokhrel, A.; Kirk, M.L.; et al. A Model for the Active-Site Formation Process in DMSO Reductase Family Molybdenum Enzymes Involving Oxido Alcoholato and Oxido Thiolato Molybdenum(VI) Core Structures. Inorg. Chem. 2016, 55, 1542-1550. [CrossRef]

43. Sugimoto, H.; Sato, M.; Giles, L.J.; Asano, K.; Suzuki, T.; Kirk, M.L.; Itoh, S. Oxo-carboxylato-molybdenum(VI) complexes possessing dithiolene ligands related to the active site of type II DMSOR family molybdoenzymes. Dalton Trans. 2013, 42, 5927-15930. [CrossRef]

44. Sugimoto, H.; Tatemoto, S.; Suyama, K.; Miyake, H.; Mtei, R.P.; Itoh, S.; Kirk, M.L. Monooxomolybdenum(VI) Complexes Possessing Olefinic Dithiolene Ligands: Probing Mo-S Covalency Contributions to Electron Transfer in Dimethyl Sulfoxide Reductase Family Molybdoenzymes. Inorg. Chem. 2010, 49, 5368-5370. [CrossRef]

45. Sugimoto, H.; Tatemoto, S.; Suyama, K.; Miyake, H.; Itoh, S.; Dong, C.; Yang, J.; Kirk, M.L. Dioxomolybdenum(VI) Complexes with Ene-1,2-dithiolate Ligands: Synthesis, Spectroscopy, and Oxygen Atom Transfer Reactivity. Inorg. Chem. 2009, 48, 10581-10590. [CrossRef]

46. Burgmayer, S.J.N.; Kim, M.; Petit, R.; Rothkopf, A.; Kim, A.; BelHamdounia, S.; Hou, Y.; Somogyi, A.; Habel-Rodriguez, D.; Williams, A.; et al. Synthesis, characterization, and spectroscopy of model molybdopterin complexes. J. Inorg. Biochem. 2007, 101, 1601-1616. [CrossRef] 
47. Kirk, M.L.; Peariso, K. Ground and excited state spectral comparisons of models for sulfite oxidase. Polyhedron 2004, 23, 499. [CrossRef]

48. Helton, M.E.; Gebhart, N.L.; Davies, E.S.; McMaster, J.; Garner, C.D.; Kirk, M.L. Thermally Driven Intramolecular Charge Transfer in an Oxo-Molybdenum Dithiolate Complex. J. Am. Chem. Soc. 2001, 123, 10389-10390. [CrossRef]

49. Davie, S.R.; Rubie, N.D.; Hammes, B.S.; Carrano, C.J.; Kirk, M.L.; Basu, P. Geometric control of reduction potential in oxomolybdenum centers: Implications to the serine coordination in DMSO reductase. Inorg. Chem. 2001, 40, 2632. [CrossRef]

50. McNaughton, R.L.; Helton, M.E.; Rubie, N.D.; Kirk, M.L. The oxo-gate hypothesis and DMSO reductase: Implications for a psuedo-sigma bonding interaction involved in enzymatic electron transfer. Inorg. Chem. 2000, 39, 4386. [CrossRef]

51. Helton, M.; Gruhn, N.; McNaughton, R.; Kirk, M. Control of oxo-molybdenum reduction and ionization potentials by dithiolate donors. Inorg. Chem. 2000, 39, 2273-2278. [CrossRef]

52. Gisewhite, D.R.; Yang, J.; Williams, B.R.; Esmail, A.; Stein, B.; Kirk, M.L.; Burgmayer, S.J.N. Implications of Pyran Cyclization and Pterin Conformation on Oxidized Forms of the Molybdenum Cofactor. J. Am. Chem. Soc. 2018, 140, 12808-12818. [CrossRef]

53. Paudel, J.; Pokhrel, A.; Kirk, M.L.; Li, F. Remote Charge Effects on the Oxygen-Atom-Transfer Reactivity and Their Relationship to Molybdenum Enzymes. Inorg. Chem. 2019, 58, 2054-2068. [CrossRef]

54. Westcott, B.L.; Gruhn, N.E.; Enemark, J.H. Evaluation of Molybdenum-Sulfur Interactions in Molybdoenzyme Model Complexes by Gas-Phase Photoelectron Spectroscopy. The "Electronic Buffer" Effect. J. Am. Chem. Soc. 1998, 120, 3382-3386. [CrossRef]

55. Wiebelhaus, N.J.; Cranswick, M.A.; Klein, E.L.; Lockett, L.T.; Lichtenberger, D.L.; Enemark, J.H. Metal-Sulfur Valence Orbital Interaction Energies in Metal-Dithiolene Complexes: Determination of Charge and Overlap Interaction Energies by Comparison of Core and Valence Ionization Energy Shifts. Inorg. Chem. 2011, 50, 11021-11031. [CrossRef]

56. Davis, M.; Olson, J.; Palmer, G. The Reaction of Xanthine Oxidase with Lumazine: Characterization of the Reductive Half-reaction. J. Biol. Chem. 1984, 259, 3526-3533. [PubMed]

57. Pauff, J.M.; Cao, H.; Hille, R. Substrate Orientation and Catalysis at the Molybdenum Site in Xanthine Oxidase Crystal structures in complex with xanthine and lumazine. J. Biol. Chem. 2009, 284, 8751-8758. [CrossRef] [PubMed]

58. Hemann, C.; Ilich, P.; Stockert, A.L.; Choi, E.Y.; Hille, R. Resonance Raman studies of xanthine oxidase: The reduced enzyme-Product complex with violapterin. J. Phys. Chem. B 2005, 109, 3023-3031. [CrossRef] [PubMed]

59. Hemann, C.; Ilich, P.; Hille, R. Vibrational spectra of lumazine in water at pH 2-13: Ab initio calculation and FTIR/Raman spectra. J. Phys. Chem. B 2003, 107, 2139-2155. [CrossRef]

60. Stein, B.W.; Yang, J.; Mtei, R.; Wiebelhaus, N.J.; Kersi, D.K.; LePluart, J.; Lichtenberger, D.L.; Enemark, J.H.; Kirk, M.L. Vibrational Control of Covalency Effects Related to the Active Sites of Molybdenum Enzymes. J. Am. Chem. Soc. 2018, 140, 14777-14788. [CrossRef]

61. Bersuker, I.B. The Jahn-Teller Effect; Cambridge University Press: Cambridge, UK, 2006.

62. Bersuker, I.B. Pseudo-Jahn-Teller Effect-A Two-State Paradigm in Formation, Deformation, and Transformation of Molecular Systems and Solids. Chem. Rev. 2013, 113, 1351-1390. [CrossRef]

(C) 2020 by the authors. Licensee MDPI, Basel, Switzerland. This article is an open access article distributed under the terms and conditions of the Creative Commons Attribution (CC BY) license (http://creativecommons.org/licenses/by/4.0/). 